\title{
Multi-Aspects Optimization of Process Parameters in CNC Turning of LM 25 Alloy Using the Taguchi-Grey Approach
}

\section{S. Dhanalakshmi * and T. Rameshbabu}

Department of Industrial Engineering, Anna University, Chennai 600 025, India; trb@annauniv.edu

* Correspondence: sdltpevr@gmail.com

Received: 18 March 2020; Accepted: 27 March 2020; Published: 31 March 2020

\begin{abstract}
LM 25 is an aluminum alloy that has numerous applications such as in the manufacturing of automobile components and food industries, and especially in marine and seawater applications, due to its exceptional properties. An exertion has been taken for attaining the best-suited group of machining variables to attain improved and better performance in machining such as increased rate of material removal, lessened roughness values at the machined surface and the total cost incurred during machining. Taguchi's design methodology has been implemented for devising the experimental combinations and also for single aspects optimization of deemed performance measures. Grey's theory concept has been adopted for attaining Grey Relational Coefficient values and the values have been further utilized for evolving Grey Relational Grade. Analysis of Variance (ANOVA) has been employed to determine the significance of input process variables on the desired performance measures and interaction analysis also has been performed to determine the interaction effect between the selected process variables. As a result of optimization, the optimal combination of cutting parameters in turning LM25 aluminum alloy is cutting speed $(A)=150.79 \mathrm{~m} / \mathrm{min}$, feed (B) $=0.15 \mathrm{~mm} / \mathrm{min}$, depth of cut $(C)=0.9 \mathrm{~mm}$ and cutting fluid flow rate $(\mathrm{D})=75 \mathrm{~mL} / \mathrm{h}$. Compared with the initial parameter settings, surface roughness (Ra) decreases by $67.97 \%$, material removal rate (MRR) increases by $88.12 \%$ and total machining cost (TMC) decreases by $93.86 \%$. The proposed approach helps the manufacturer to attain better machining performance at an affordable cost.
\end{abstract}

Keywords: LM 25 alloy; CNC turning; Taguchi's design of experiments; parameters optimization; economic analysis; interaction analysis; ANOVA analysis; Grey Relational Approach

\section{Introduction}

Aluminum alloys comprising "Si" as a chief alloying constituent that structures a group of material offers the most noteworthy part of all casting made materials. These are alloys most commonly adopted in various engineering fields namely as automobile and aerospace industries because of their exceptional mechanical behavior as well as their resistance to corrosive environments [1]. The reduction of vehicle weight is getting more important because of commercial and environmental needs. Al-Si cast alloys are best-suited material for fulfilling such objectives and opted for the manufacturing of automobile components at minimum cost with improved specific strength and its recycling ability [2-4]. Machining is the process that involves various input/output parameters for attaining the desired performance measures. A suitable choice of process variables/levels helps the industry people to obtain proper control over the various independent variables [5]. Various researchers have performed analysis on machining of aluminum alloys with minimum lubricant conditions/dry machining conditions [6-11]. An extensive study on microstructural changes to BUL and BUE variations in the turning process has been performed for aluminum alloy [12]. 
In a turning process, various parameters named as cutting speed, feed, depth of cut and tool geometry are competing variables and took part in the decisive role in flank wear [13,14]. The surface finish of the machine area is developed by an increase in depth of cut, and for attaining it, the cutting speed must be kept at a possible maximum level [15]. An investigation has been performed for analyzing the impact of cutting speed, feed and nose radius for ascertaining the best-suited parameters' amalgamation in the turning process for better and enhanced surface finish [16]. Qiu et al. explored experimentally the influence of process variables for aluminum alloy and also revealed that the rise in the speed of machining and feed on the tool initially tends to worsen as the tendency throughout acceleration is increased in all directions [17]. An in-process prediction monitoring approach has been employed for analyzing the vibration analysis in the turning of titanium alloys. The empirical relations were evolved for multiple responses to envisage the surface finish of the machined zone [18]. At present, all the methods of machining must fulfill the extreme requirements of manufacturing containing the performance of machining, finish obtained from the machining, consumption of energy and standards of ecological environments. Most of the machining is a complex process, since it has multiple aspects that are characterized by its unique capabilities in the processing of materials. The selection of machining methods is decided by the criteria that are considered for machining processes such as production cost, volume, preferred quality of component to be produced, etc. For dealing with numerous controversial process variables, the researchers adopted multiple criteria decision-making methods that help to resolve the various decision-making problems [19]. Among the numerous MCDM methods available, the Grey Relational Analysis method has been employed for resolving multi-performance aspects. Grey theory has been proposed and it is proved to be a fruitful approach for dealing with incomplete and unclear data [20-23]. Apart from these various variables related to machining, cost-effectiveness is an important factor to be considered for making an economic analysis in machining. Proper control of independent variables results in effective control on the cost of the machining. Change in the values of cutting speed/feed influences the processing time that consequently results in an increase of tooling costs. Various research has been performed on controlling the cost of machining by considering multiple aspects such as reducing cost, time of production and roughness of the machined zone. A geometric-program-based method has been adopted to minimize the cost of machining and tooling [24-27].

It is surmised from the literature, that there is a lack of investigation performed on multi-aspect optimization of process variables using the Taguchi-based Grey approach by considering the performance measures namely material removal rate (MRR), surface roughness (SR) and cost analysis for the CNC turning of LM 25 alloy. The economic analysis of the machining process occupies an imperative part in the production and quality control of a product. The effective measurement and evaluation of cost analysis as a performance measure needs attention. The Taguchi-based Grey Relational Analysis (GRA) approach is employed to determine the Grey Coefficient Values.

In this present article, an endeavor has been made to develop the multi-aspects optimization model by means of the Taguchi-Grey approach for the CNC turning of LM 25 alloy.

\section{Materials and Methods}

LM25 is an aluminum alloy that has better resistance to corrosive environments and also possesses better tensile strength, deemed as a work material in this exploration, and it is employed in various engineering applications such as automotive parts (cylinder blocks, cylinder heads) and also in food processing industries. Apart from all of these, LM25 alloy was adopted due to its better mechanical behavior and better machinability while comparing with LM6 alloys. The chemical composition of LM25 alloy is depicted in Table 1 and it is confirmed with EDAX analysis. 
Table 1. Chemical composition of LM 25 aluminum alloy.

\begin{tabular}{cccccccccc}
\hline $\mathbf{A l}$ & $\mathbf{C u}$ & $\mathbf{M g}$ & $\mathbf{S i}$ & $\mathbf{F e}$ & $\mathbf{M n}$ & $\mathbf{N i}$ & $\mathbf{Z n}$ & $\mathbf{P b}$ & $\mathbf{S n}$ \\
\hline $91.75 \%$ & $0.1 \%$ & $0.5 \%$ & $6.5 \%$ & $0.5 \%$ & $0.3 \%$ & $0.1 \%$ & $0.1 \%$ & $0.1 \%$ & $0.05 \%$ \\
\hline
\end{tabular}

The experimentation was accomplished on the CNC turning center (Make: Mac Power CNC, Model: Mono 300, Ahonol-7 as cutting fluid) by considering various independent process parameters. The opted process variables and their levels are exhibited in Table 2.

Table 2. Process parameters and levels.

\begin{tabular}{ccccc}
\hline \multirow{2}{*}{ Symbols } & Parameters & \multicolumn{3}{c}{ Levels } \\
\cline { 3 - 5 } & & $\mathbf{1}$ & $\mathbf{2}$ & $\mathbf{3}$ \\
\hline \multirow{2}{*}{$\mathrm{A}$} & Cutting speed (V), rpm & 500 & 1000 & 1500 \\
$\mathrm{~B}$ & Cutting Speed (V), m/min & 50.23 & 100.53 & 150.79 \\
C & Feed (F), $\mathrm{mm} / \mathrm{min}$ & 0.1 & 0.15 & 0.2 \\
$\mathrm{D}$ & Depth of cut (D), mm & 0.3 & 0.6 & 0.9 \\
& Cutting fluid flow rate (CF), $\mathrm{mL} / \mathrm{h}$ & 65 & 75 & 85 \\
\hline
\end{tabular}

The experiments were devised by Taguchi's approach. An L27 Orthogonal Array (OA) was chosen for performing experimental runs. A holder for holding the tool and Tungsten Carbide tool insert, which possesses the ISO designation of PCLNL 1616 H12 and CNMG120408-GM, were used. The experimental setup and tool geometry utilized for machining are exhibited in Figure 1.

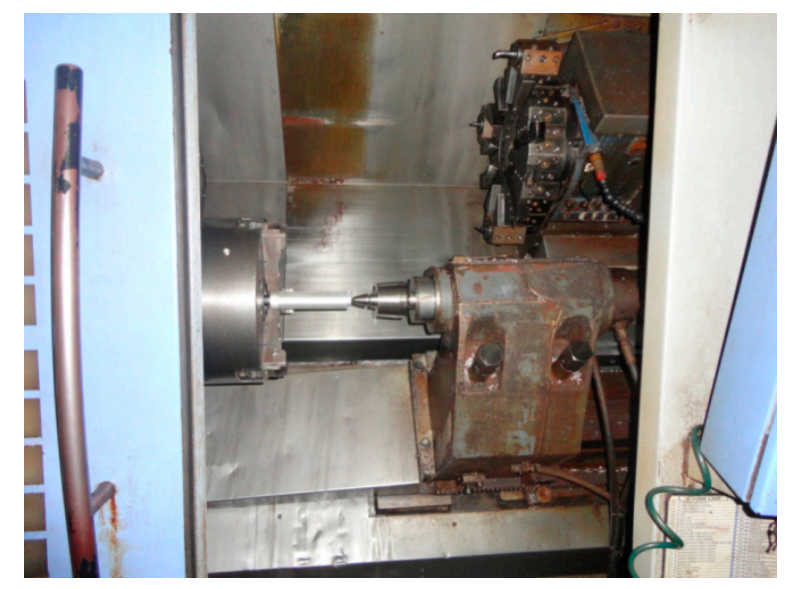

(a)

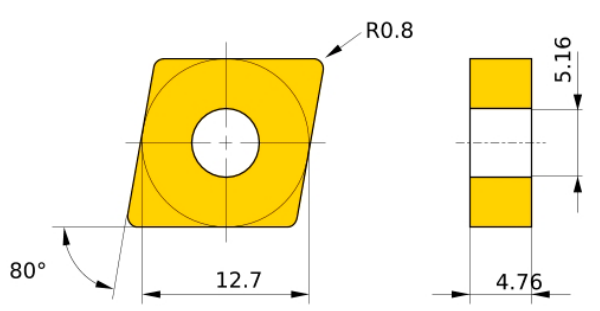

(b)

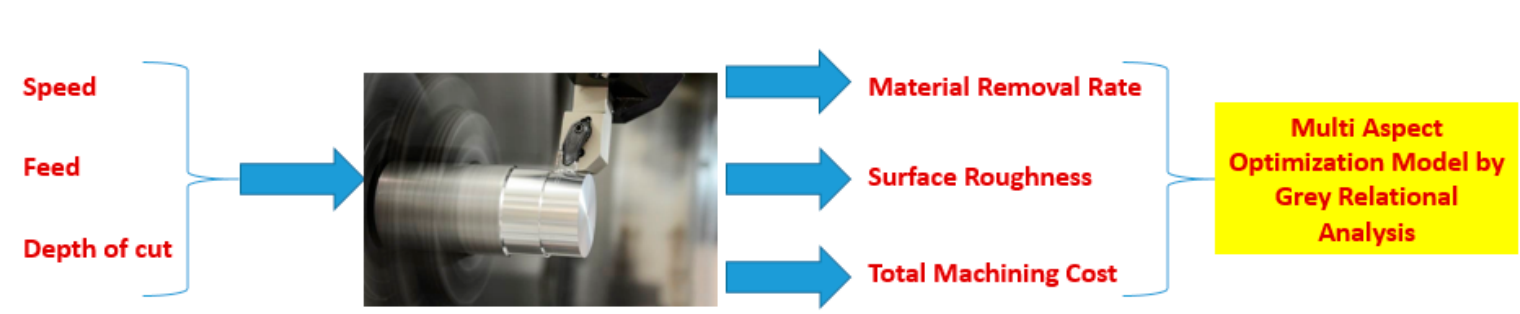

(c)

Figure 1. (a) Experimental setup with (b) tool geometry in mm CNMG120408-GM and (c) procedural steps of the turning of LM 25. 
The removal rate of the material was assessed by a weight loss method. The roughness (Ra) of the machined surface was evaluated by a contact type roughness testing device (Kosaka Make-Model SE 600, (Kosaka Laboratory, Tokyo, Japan) as shown in Figure 2. The experiments were conducted thrice and average values were considered for further analysis. Ahonol-7 was the cutting fluid employed for conducting experiments and supplied at the minimum level for ensuring the near-dry cutting environment with the help of burette attachment.

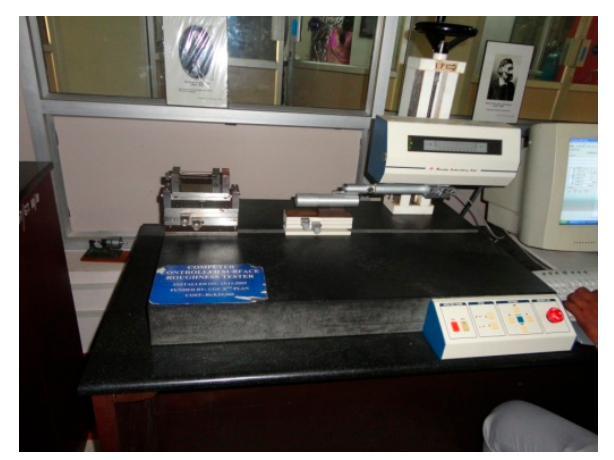

(a)

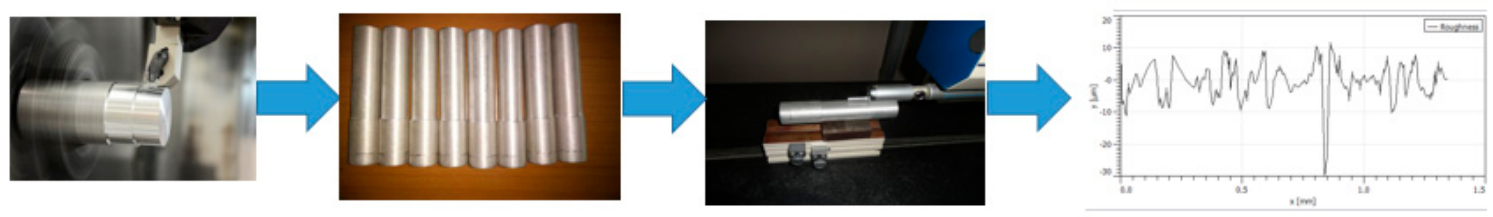

(b)

Figure 2. (a) Surface roughness testing (b) Flow chart of surface roughness measurement.

Optimization is useful to ascertain the optimal parameter settings of particular processes. Practically, more intention is to reduce the manufacturing cost. Hence, it becomes essential to show that optimization aids in reducing the cost incurred during production. The present exploration details the role of optimization in minimizing the economic burden of the industrialists. The optimal parameter setting obtained in turning LM 25 alloy using Grey Relational Analysis was used for calculating the total machining cost. Total machining cost was computed for all the 27 experimental trials.

\subsection{Grey Relational Analysis (GRA)}

GRA is a multi-criterion decision-making methodology that is espoused for resolving the multi-characteristic optimization issues and it is an effective technique for numerous machining processes.

Step 1: The desired quality characteristics for MRR is maximum are better; for normalizing this wanted performance characteristic, Equations (1) and (2) were employed as minimum for the better criterion (roughness and cost of machining).

$$
Y_{p q}=\left(\frac{X_{p q}-\operatorname{Min}\left(X_{p q}\right)}{\operatorname{Max}\left(X_{p q}\right)-\operatorname{Min}\left(X_{p q}\right)}\right)
$$




$$
Y_{i j}=\left(\frac{\operatorname{Max}\left(X_{p q}\right)-X_{p q}}{\operatorname{Max}\left(X_{p q}\right)-\operatorname{Min}\left(X_{p q}\right)}\right)
$$

where $X_{p q}$ is the dependent variable, $\min \left(X_{p q}\right)$ is the smallest value of $X_{p q}$ and $\max \left(X_{p q}\right)$ is the uppermost value of $X_{p q ;} p$ is the dependent variable and " $q$ " is the run number of experimentations. Fundamentally, exploited normalized values are signs of healthier the performance characteristics.

Step 2: The supreme values from the normalization regardless of response process variables experimental runs are evaluated by Equation (3).

$$
R=\operatorname{Max}\left(Y_{p q}\right)
$$

Step 3: The complete variance among the reference sequence value $\mathrm{R}$ and each value from normalization is appraised by Equation (4):

$$
\Delta_{p q}=\left|Y_{p q}-R\right|
$$

where " $R$ " is the expected sequence, " $Y_{p q}$ " is the comparability sequence and " $\Delta_{p q}$ " is the deviation sequence of $R$ and $Y_{p q}$.

Step 4: The Grey Relation Coefficient (GRC) $\xi_{p q}$ for each of the normalized values is computed using Equation (5).

$$
\xi_{p q}=\left(\frac{\operatorname{Min}\left(\Delta_{p q}\right)+\zeta \operatorname{Max}\left(\Delta_{p q}\right)}{\Delta_{p q}+\zeta \operatorname{Max}\left(\Delta_{p q}\right)}\right)
$$

where " $\zeta$ " is the differentiating coefficient, " $\zeta$ " $\in[0,1]$ and 0.5 is the usually recognized value. Superior the values of GRC means the relational degree will be persuasive.

Step 5: The Grey Relational Grade (GRG) for each experimental run is calculated as follows in Equation (6):

$$
\gamma_{j}=\frac{\sum_{i=1}^{n} \xi_{p q}}{n}
$$

where " $n$ " is the number of response variables.

The GRG " $\gamma j$ " indicates the degree of closeness of the relationship among the reference sequence and the comparative sequence. If an upper value of GRG is obtained, then the corresponding combination of the process variable is nearer to the most satisfactory for attaining improved performance [28].

\subsection{Procedure for Economic Analysis in Turning Operation}

This section presents the economic index for the machining process considering the parameters cutting speed, feed, depth of cut and cutting fluid flow rate. The cost component considered in this analysis includes part handling cost (C1), labor cost (C2), labor machining cost (C3), coolant cost (C4), tooling cost (C5) and machine cost (C6).

The data presented in the Table 3 given below was made available by referencing the detailed specifications of the process plan, and by gathering information from machinists and process operators. In addition, for some of the inputs/outputs in the process plan, one of the following sources was used: measurement or estimation based on initial/final part geometry and discussions with machine operators. 
Table 3. Data used in machining calculations.

\begin{tabular}{clc}
\hline S. No. & \multicolumn{1}{c}{ Measure } & Value \\
\hline 1 & Length of component $(\mathrm{L})$ & $150 \mathrm{~mm}$ \\
2 & Initial diameter of component $\left(\mathrm{D}_{\mathrm{i}}\right)$ & $32 \mathrm{~mm}$ \\
3 & Density of component $(\rho)$ & $2.68 \mathrm{~g} / \mathrm{cm}^{3}$ \\
4 & Number of edges per insert & 4 \\
7 & Cost of insert & Rs. 25000 \\
8 & Cost of coolant & Rs. $250 / 1$ \\
9 & Cost of material used for production & Rs. $90 / \mathrm{Kg}$ \\
10 & Cost of CNC machine used for experiments & Rs. $2,500,000$ \\
11 & Observed CNC machine life in Industry & 15 years \\
12 & Salvage value of CNC machine & Rs. 400,000 \\
13 & Working hours in a day & $8 \mathrm{~h}$ \\
14 & Labor charges $\left(\mathrm{C}_{\mathrm{L}}\right)$ & Rs. $0.5 / \mathrm{min}$ \\
15 & Machine running charges $\left(\mathrm{C}_{\mathrm{MR}}\right)$ & Rs. $0.25 / \mathrm{min}$ \\
\hline
\end{tabular}

Part handling cost $\left(\mathrm{C}_{1}\right)$

This cost component includes labor charges spent for loading, unloading the part and cleaning chips in the machining area.

Machine running cost $\left(C_{2}\right)$

The cost spent on machining a component is considered here.

Labor machining cost $\left(\mathrm{C}_{3}\right)$

This involves the period during which the actual cutting process takes place.

$$
\mathrm{C}_{3}=\left(\mathrm{C}_{\mathrm{L}}+\mathrm{C}_{\mathrm{MR}}\right) \times \mathrm{T}_{\mathrm{c}} / \text { comp }
$$

Coolant cost $\left(\mathrm{C}_{4}\right)$

Coolant cost is computed by the product of the quantity of coolant used in each experimental trial and the cost of coolant.

$$
\mathrm{C}_{4}=\text { Quantity of coolant consumed } \times \text { Cost of coolant }
$$

Tooling cost $\left(\mathrm{C}_{5}\right)$

In this study, disposable inserts were used and the expression for tool cost is based on the cost of one insert $(\mathrm{P})$ and the number of cutting edges per insert ( $\mathrm{N}$ edges) and the number of components turned per edge $\left(\mathrm{N}_{\mathrm{p}}\right)$.

$$
C_{5}=\frac{P}{\text { NedgeXNp }}
$$

Machine cost $\left(\mathrm{C}_{6}\right)$

In this head, the utilization cost of the machine is taken into consideration. It is calculated by

$$
\text { Machine cost }=\text { Machine running cost }+ \text { Machine overhead cost }
$$

As per the suggestions from the experts and operators, the machine overhead cost is accounted for as $10 \%$ of the machine running cost.

Total Machining Cost

It is the summation of the labor machining cost $\left(C_{3}\right)$, coolant cost $\left(C_{4}\right)$, tooling $\operatorname{cost}\left(C_{5}\right)$ and the machine cost $\left(\mathrm{C}_{6}\right)$ involved in producing a part.

$$
\text { Total machining cost }(\mathrm{TMC})=\mathrm{C}_{3}+\mathrm{C}_{4}+\mathrm{C}_{5}+\mathrm{C}_{6}
$$




\section{Results and Discussion}

The experimental runs were accomplished as per L27 OA used for exploring the prominence of independent variables on desired performance characteristics in the CNC turning of LM25 aluminum alloy. The experimental layout with observations is depicted in Table 4. An exertion was made for ascertaining the best probable combination of process variables for accomplishing the efficacious and competent CNC turning process. In the CNC turning process, the greater the removal rate of the material, the lesser the values of surface roughness and the smaller the cost of the indicator of superior performance measures. So, for MRR, the larger the better the criterion, and for surface roughness and total machining cost, the smaller the better the criterion.

Table 4. Experimental layout with observations.

\begin{tabular}{|c|c|c|c|c|c|c|c|}
\hline $\begin{array}{l}\text { Trial } \\
\text { No. }\end{array}$ & $\begin{array}{c}\mathrm{A} \\
(\mathrm{rpm})\end{array}$ & $\begin{array}{c}\text { B } \\
(\mathrm{mm} / \mathrm{min})\end{array}$ & $\begin{array}{c}\mathrm{C} \\
(\mathrm{mm})\end{array}$ & $\begin{array}{c}\mathrm{D} \\
(\mathrm{mL} / \mathrm{h})\end{array}$ & $\begin{array}{c}\text { Material Removal } \\
\text { Rate }\left(\mathrm{mm}^{3} / \mathrm{s}\right)\end{array}$ & $\begin{array}{c}\text { Surface Roughness } \\
\text { (Ra) (Microns) }\end{array}$ & $\begin{array}{c}\text { TMC } \\
\text { (Rupees) }\end{array}$ \\
\hline 1 & 500 & 0.1 & 0.3 & 65 & 2.685 & 4.09 & 11.734 \\
\hline 2 & 500 & 0.1 & 0.6 & 75 & 2.826 & 4.24 & 12.481 \\
\hline 3 & 500 & 0.1 & 0.9 & 85 & 2.558 & 4.30 & 11.538 \\
\hline 4 & 500 & 0.15 & 0.3 & 75 & 5.642 & 2.68 & 7.227 \\
\hline 5 & 500 & 0.15 & 0.6 & 85 & 6.212 & 2.70 & 6.694 \\
\hline 6 & 500 & 0.15 & 0.9 & 65 & 5.610 & 2.69 & 7.963 \\
\hline 7 & 500 & 0.2 & 0.3 & 85 & 11.873 & 3.51 & 5.053 \\
\hline 8 & 500 & 0.2 & 0.6 & 65 & 11.931 & 3.44 & 4.758 \\
\hline 9 & 500 & 0.2 & 0.9 & 75 & 12.139 & 3.55 & 4.501 \\
\hline 10 & 1000 & 0.1 & 0.3 & 75 & 7.976 & 3.33 & 4.710 \\
\hline 11 & 1000 & 0.1 & 0.6 & 85 & 8.333 & 3.32 & 4.604 \\
\hline 12 & 1000 & 0.1 & 0.9 & 65 & 8.244 & 3.52 & 4.574 \\
\hline 13 & 1000 & 0.15 & 0.3 & 85 & 24.874 & 2.30 & 3.350 \\
\hline 14 & 1000 & 0.15 & 0.6 & 65 & 23.903 & 2.27 & 2.959 \\
\hline 15 & 1000 & 0.15 & 0.9 & 75 & 24.189 & 2.36 & 3.135 \\
\hline 16 & 1000 & 0.2 & 0.3 & 65 & 9.154 & 3.67 & 2.292 \\
\hline 17 & 1000 & 0.2 & 0.6 & 75 & 9.140 & 3.28 & 2.247 \\
\hline 18 & 1000 & 0.2 & 0.9 & 85 & 9.964 & 3.34 & 2.170 \\
\hline 19 & 1500 & 0.1 & 0.3 & 85 & 22.426 & 2.12 & 3.114 \\
\hline 20 & 1500 & 0.1 & 0.6 & 65 & 22.517 & 2.19 & 3.042 \\
\hline 21 & 1500 & 0.1 & 0.9 & 75 & 22.261 & 2.16 & 3.114 \\
\hline 22 & 1500 & 0.15 & 0.3 & 65 & 3.629 & 2.22 & 2.127 \\
\hline 23 & 1500 & 0.15 & 0.6 & 75 & 3.688 & 2.22 & 2.077 \\
\hline 24 & 1500 & 0.15 & 0.9 & 85 & 4.043 & 2.23 & 2.059 \\
\hline 25 & 1500 & 0.2 & 0.3 & 75 & 24.472 & 3.83 & 1.968 \\
\hline 26 & 1500 & 0.2 & 0.6 & 85 & 23.760 & 3.89 & 1.694 \\
\hline 27 & 1500 & 0.2 & 0.9 & 65 & 24.300 & 3.96 & 1.661 \\
\hline
\end{tabular}

\subsection{Influence of Process Variables on Material Removal Rate}

The analysis diagram for the rate of material removal during machining of the CNC turning of LM25 alloy is exhibited in Figure 3. The outcomes obtained from the experimentation reveals that the feed has more influence on the MRR. Since the feed is the distance moved per rotation of the work material, it shows the duration for removing material. Henceforth, due to more feed, the time taken for removing the material from the work material for a specified length results in the upsurge in the MRR. As the cutting speed increases consequently influences the MRR proportionally. The more depth results in an increased rate of material because the removed chips per unit time will be more and, hence, the removed material will be high. 


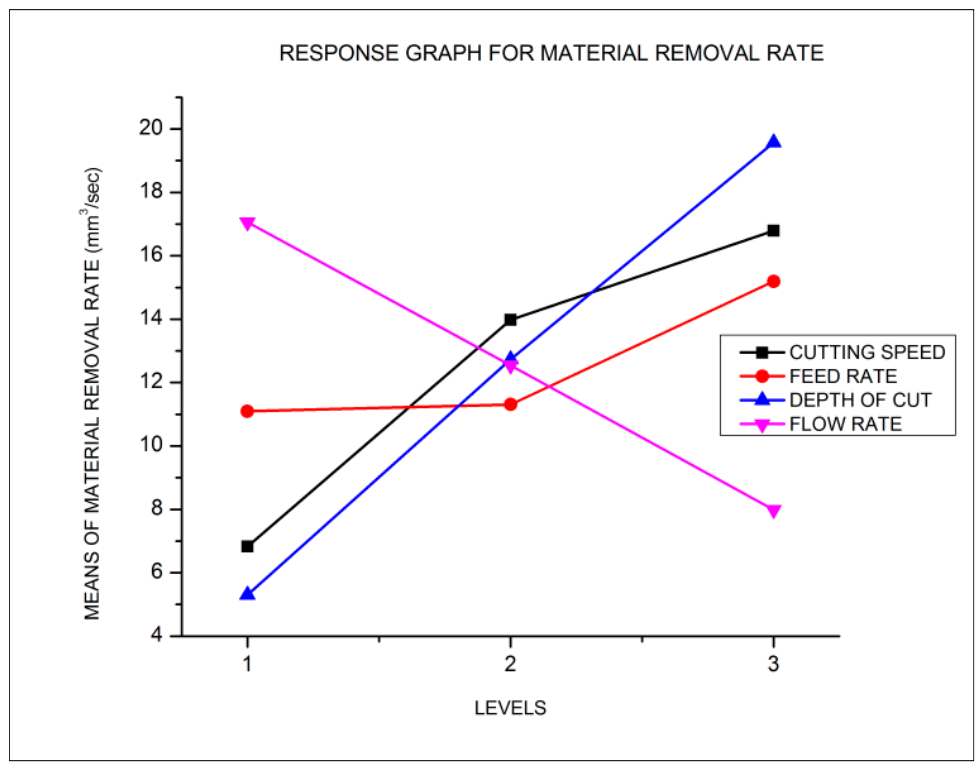

Figure 3. Analysis on material removal rate.

The response analysis has been adopted for analyzing a single response and the outcomes are depicted in Table 5. The optimum combination for attaining better and improved material removal rate are $A_{3} B_{3} C_{3} D_{1}$, i.e., maximum levels of speed, feed, and depth of cut given and minimum values of flow rate produce an increased rate of material removal.

Table 5. Response table for material removal rate.

\begin{tabular}{ccccc}
\hline Levels & Cutting Speed $(\mathbf{r p m})$ & Feed $(\mathbf{m m} / \mathbf{m i n})$ & Depth of Cut $(\mathbf{m m})$ & Flow Rate $(\mathbf{m L} / \mathbf{h})$ \\
\hline 1 & 6.831 & 11.092 & 5.299 & 17.063 \\
2 & 13.975 & 11.31 & 12.728 & 12.547 \\
3 & 16.788 & 15.193 & 19.568 & 7.984 \\
\hline Delta & 9.958 & 4.101 & 14.27 & 9.079 \\
\hline Rank & 2 & 4 & 1 & 3 \\
\hline
\end{tabular}

\subsection{Influence of Process Variables on Surface Roughness}

The analysis diagram for surface roughness during machining of the CNC turning of LM25 is displayed in Figure 4. The roughness of the machined area has been reduced with the escalation in cutting speed, and there is a better surface roughness trend observed with the amalgamation of the upper speed of cutting and lower cutting depth. Increase in feed results in an upsurge in values of roughness. This happens due to the generation of heat that consequently results in tool wear that results in more surface roughness. The same thing has the tendency of increasing the chatter and makes the imperfect machining at higher speed results in greater values of roughness.

The usage of cutting fluid helps the machining process to lessen the machining temperature for enhancing the life of the tool and provides better surface finish and also it indirectly helps to improve environmental conditions and also economic consequences. The response analysis has been adopted for analyzing a single response and the outcomes are depicted in Table 6. The optimum values of combination for attaining better and improved surface finish are $A_{1} B_{3} C_{2} D_{1}$. 


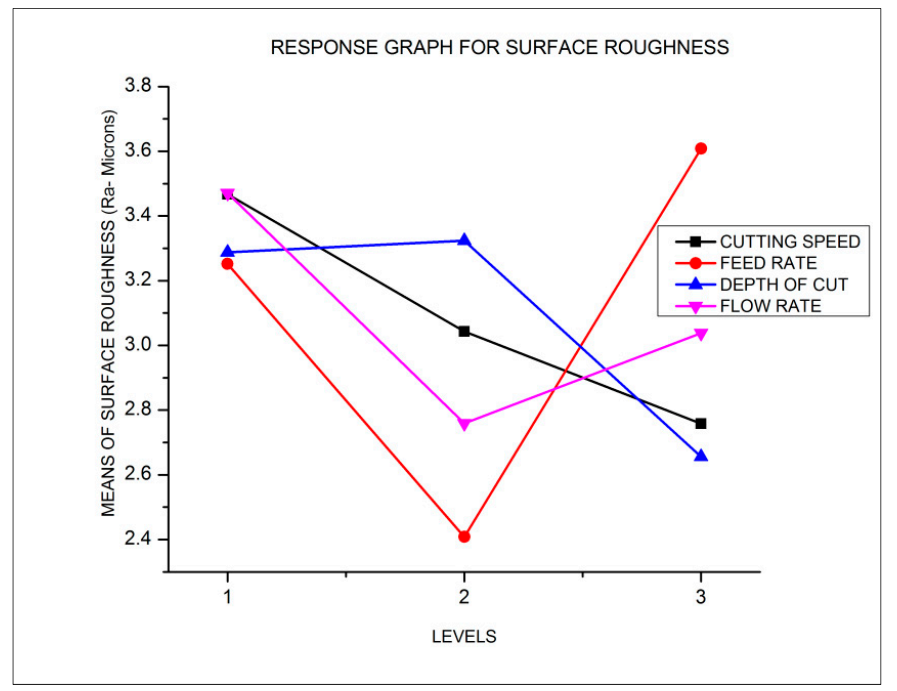

Figure 4. Analysis on surface roughness.

Table 6. Response table for surface roughness.

\begin{tabular}{ccccc}
\hline Levels & Cutting Speed & Feed & Depth of Cut & Flow Rate \\
\hline 1 & 3.467 & 3.252 & 3.288 & 3.471 \\
2 & 3.043 & 2.408 & 3.324 & 2.759 \\
3 & 2.758 & 3.608 & 2.656 & 3.038 \\
\hline Delta & 0.709 & 1.2 & 0.669 & 0.712 \\
\hline Rank & 3 & 1 & 4 & 2 \\
\hline
\end{tabular}

\subsection{Influence of Process Variables on Total Machining Cost}

The analysis graph for total machining cost during machining of the CNC turning of LM25 alloy is shown in Figure 5. The cost of machining is lower at maximum levels of cutting speed, feed, depth of cut given and rate of flow of cooling liquid. The increase in cutting speed, feed and depth of cut makes the completion of products within a minimum possible duration, which helps to reduce the machining cost and consequently reduces the overall machining cost.

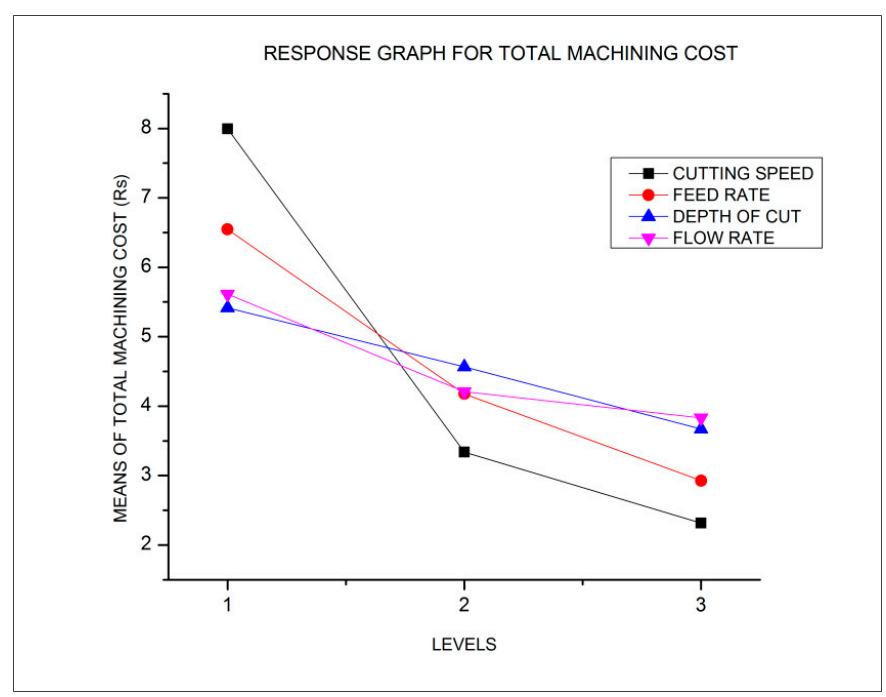

Figure 5. Analysis on total machining cost. 
An increase in supply of cooling rate produces a comparatively lower cost than the remaining cutting conditions. More supply of cooling liquid leads to an increase in the quantity of liquid requirements. Comparatively, all these combinations produce the component with a minimum possible cost. The response analysis has been adopted for analyzing a single response and the outcomes are depicted in Table 7 . The optimum values of combination for attaining minimum machining cost are $\mathrm{A}_{1} \mathrm{~B}_{1} \mathrm{C}_{1} \mathrm{D}_{1}$.

Table 7. Response table for total machining cost.

\begin{tabular}{ccccc}
\hline Levels & Cutting Speed & Feed & Depth of Cut & Flow Rate \\
\hline 1 & 7.994 & 6.546 & 5.414 & 5.613 \\
2 & 3.338 & 4.177 & 4.566 & 4.207 \\
3 & 2.317 & 2.927 & 3.67 & 3.829 \\
\hline Delta & 5.677 & 3.619 & 1.744 & 1.784 \\
\hline Rank & 1 & 2 & 4 & 3 \\
\hline
\end{tabular}

\subsection{Multi-Response Optimization}

The multi-objective optimization on the CNC turning of LM25 alloy by applying the Taguchi-based Grey approach is done and detailed in this section. The GRC and GRG values for the CNC turning of LM25 alloy are assessed with the help of Equations (5) and (6) and are graded as depicted in Table 8.

Table 8. Multi-aspects optimization outcomes by Grey Relational Analysis (GRA).

\begin{tabular}{|c|c|c|c|c|c|c|c|c|c|}
\hline \multirow{2}{*}{ Exp No. } & \multirow{2}{*}{$\underset{(\mathrm{rpm})}{\mathrm{A}}$} & \multirow{2}{*}{$\begin{array}{c}\text { B } \\
(\mathrm{mm} / \mathrm{min})\end{array}$} & \multirow{2}{*}{$\begin{array}{c}\mathrm{C} \\
(\mathrm{mm})\end{array}$} & \multirow{2}{*}{$\begin{array}{c}\mathrm{D} \\
(\mathrm{mL} / \mathrm{h})\end{array}$} & \multicolumn{3}{|c|}{ GRC } & \multirow{2}{*}{ GRG } & \multirow{2}{*}{ Rank } \\
\hline & & & & & MRR & SR & TMC & & \\
\hline 1 & 500 & 0.10 & 0.3 & 65 & 0.3346 & 0.3562 & 0.3494 & 0.3467 & 25 \\
\hline 2 & 500 & 0.10 & 0.3 & 65 & 0.3360 & 0.3396 & 0.3333 & 0.3363 & 27 \\
\hline 3 & 500 & 0.10 & 0.3 & 65 & 0.3333 & 0.3333 & 0.3539 & 0.3402 & 26 \\
\hline 4 & 500 & 0.15 & 0.6 & 75 & 0.3672 & 0.6606 & 0.4929 & 0.5069 & 20 \\
\hline 5 & 500 & 0.15 & 0.6 & 75 & 0.3742 & 0.6527 & 0.5181 & 0.5150 & 18 \\
\hline 6 & 500 & 0.15 & 0.6 & 75 & 0.3668 & 0.6566 & 0.4619 & 0.4951 & 24 \\
\hline 7 & 500 & 0.20 & 0.9 & 85 & 0.4619 & 0.4395 & 0.6146 & 0.5053 & 21 \\
\hline 8 & 500 & 0.20 & 0.9 & 85 & 0.4630 & 0.4523 & 0.6359 & 0.5171 & 17 \\
\hline 9 & 500 & 0.20 & 0.9 & 85 & 0.4670 & 0.4325 & 0.6558 & 0.5184 & 16 \\
\hline 10 & 1000 & 0.10 & 0.6 & 85 & 0.3977 & 0.4739 & 0.6396 & 0.5037 & 22 \\
\hline 11 & 1000 & 0.10 & 0.6 & 85 & 0.4028 & 0.4760 & 0.6477 & 0.5088 & 19 \\
\hline 12 & 1000 & 0.10 & 0.6 & 85 & 0.4015 & 0.4378 & 0.6500 & 0.4964 & 23 \\
\hline 13 & 1000 & 0.15 & 0.9 & 65 & 1.0000 & 0.8583 & 0.7621 & 0.8734 & 1 \\
\hline 14 & 1000 & 0.15 & 0.9 & 65 & 0.9199 & 0.8790 & 0.8065 & 0.8685 & 3 \\
\hline 15 & 1000 & 0.15 & 0.9 & 65 & 0.9422 & 0.8195 & 0.7859 & 0.8492 & 6 \\
\hline 16 & 1000 & 0.20 & 0.3 & 75 & 0.4151 & 0.4129 & 0.8955 & 0.5745 & 15 \\
\hline 17 & 1000 & 0.20 & 0.3 & 75 & 0.4149 & 0.4844 & 0.9023 & 0.6005 & 14 \\
\hline 18 & 1000 & 0.20 & 0.3 & 75 & 0.4280 & 0.4719 & 0.9140 & 0.6046 & 13 \\
\hline 19 & 1500 & 0.10 & 0.9 & 75 & 0.8201 & 1.0000 & 0.7883 & 0.8695 & 2 \\
\hline 20 & 1500 & 0.10 & 0.9 & 75 & 0.8256 & 0.9397 & 0.7966 & 0.8540 & 5 \\
\hline 21 & 1500 & 0.10 & 0.9 & 75 & 0.8103 & 0.9646 & 0.7883 & 0.8544 & 4 \\
\hline 22 & 1500 & 0.15 & 0.3 & 85 & 0.3444 & 0.9160 & 0.9207 & 0.7270 & 11 \\
\hline 23 & 1500 & 0.15 & 0.3 & 85 & 0.3450 & 0.9160 & 0.9286 & 0.7298 & 9 \\
\hline 24 & 1500 & 0.15 & 0.3 & 85 & 0.3488 & 0.9083 & 0.9315 & 0.7295 & 10 \\
\hline 25 & 1500 & 0.20 & 0.6 & 65 & 0.9652 & 0.3893 & 0.9463 & 0.7669 & 7 \\
\hline 26 & 1500 & 0.20 & 0.6 & 65 & 0.9092 & 0.3811 & 0.9939 & 0.7614 & 8 \\
\hline 27 & 1500 & 0.20 & 0.6 & 65 & 0.9511 & 0.3720 & 0.7898 & 0.7043 & 12 \\
\hline
\end{tabular}


Trial No. 13 possessing the upper GRG value shows better performance compared with the remaining set of process variables' combination and is deemed the best suitable combination of the process variables for attaining improved performance [28].

The calculated GRG is considered as a single objective function. The response analysis has been adopted for analyzing a single response and the results are depicted in Table 9 and graphically in Figure 6. The optimum values of the combination for attaining multi-performance characteristics are $\mathrm{A}_{3} \mathrm{~B}_{2} \mathrm{C}_{3} \mathrm{D}_{2}$.

Table 9. Response table for Grey Relational Grade.

\begin{tabular}{ccccc}
\hline Levels & Cutting Speed & Feed & Depth of Cut & Flow Rate \\
\hline 1 & 0.4534 & 0.5678 & 0.5543 & 0.6497 \\
2 & 0.6533 & 0.6994 & 0.5843 & 0.6527 \\
3 & 0.7774 & 0.6170 & 0.7455 & 0.5818 \\
\hline Delta & 0.324 & 0.1316 & 0.1912 & 0.0709 \\
\hline Rank & 1 & 3 & 2 & 4 \\
\hline
\end{tabular}

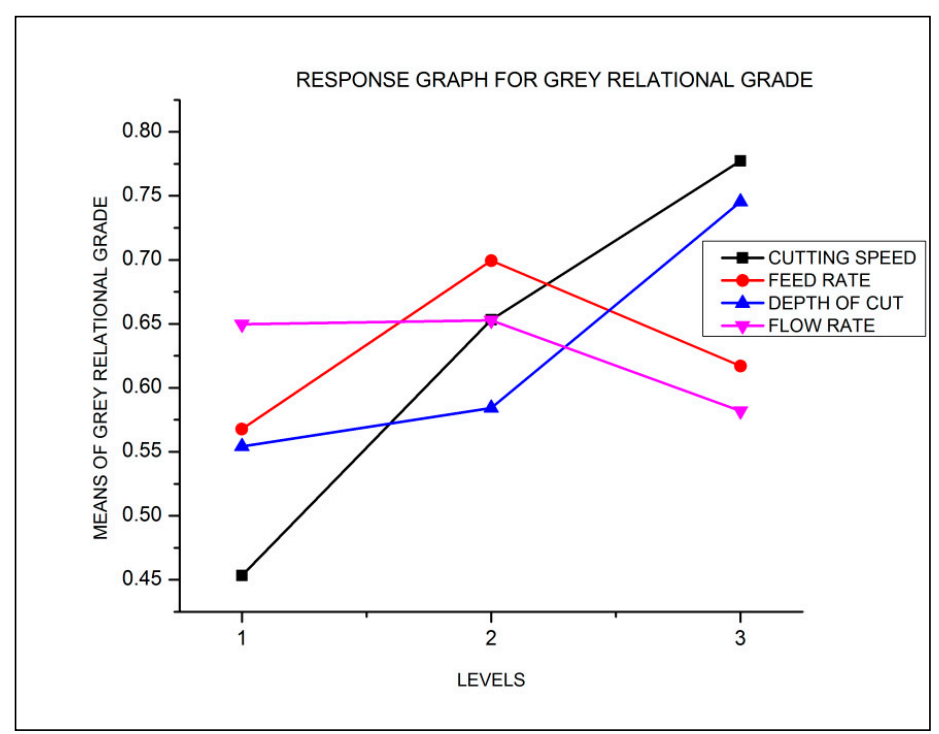

Figure 6. Analysis on Grey Relational Grades.

\subsection{Interaction Analysis on Desired Performance Measures}

Interaction analysis has been performed for determining the interaction influence of process variables on the desired performance measures. The interaction plots for material removal rate, surface roughness and total machining cost are depicted in Figures 7-9 respectively.

In order to determine whether two process parameters are interacting or not, one can use a simple but powerful graphical tool called interaction graphs. If the lines in the interaction plot are parallel, there is no interaction between the process parameters. This implies that the change in the mean response from low to high level of a factor does not depend on the level of the other factor. On the other hand, if the lines are non-parallel, an interaction exists between the factors. The greater the degree of departure from being parallel, the stronger the interaction effect. So, Non-parallel line is the indication of presence of interaction between two variables [29]. It is observed from the interaction plot that the factors of various combinations at all levels makes an interaction effect on material removal rate and surface roughness. From Figure 9, it is perceived from the interaction plot for the total machining cost the combinations of feed, depth of cut and flow rate at all levels. 


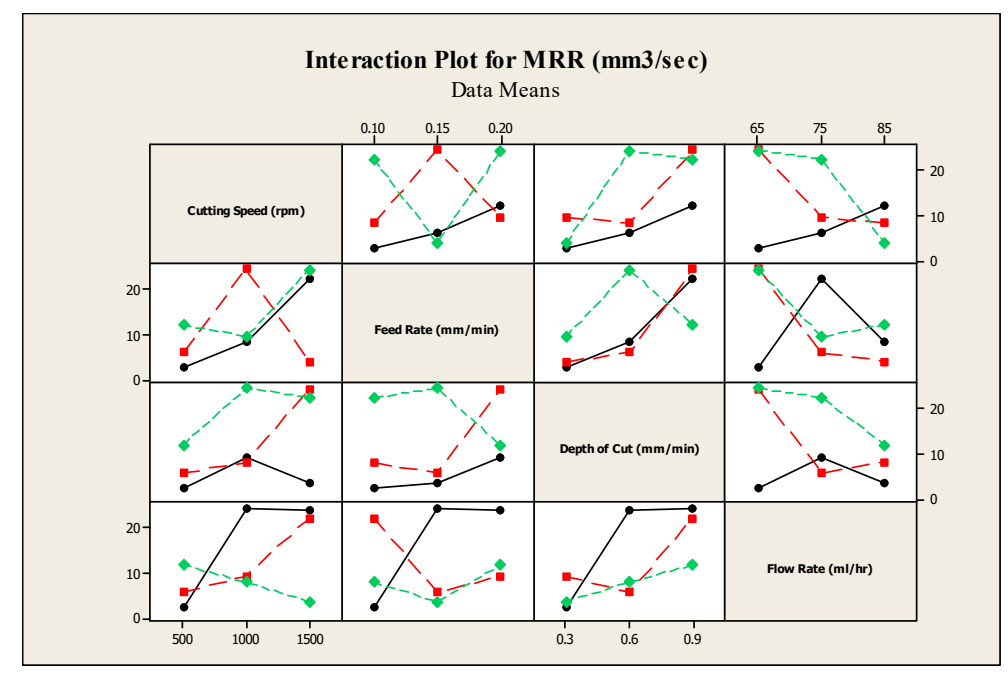

Figure 7. Interaction plot for material removal rate.

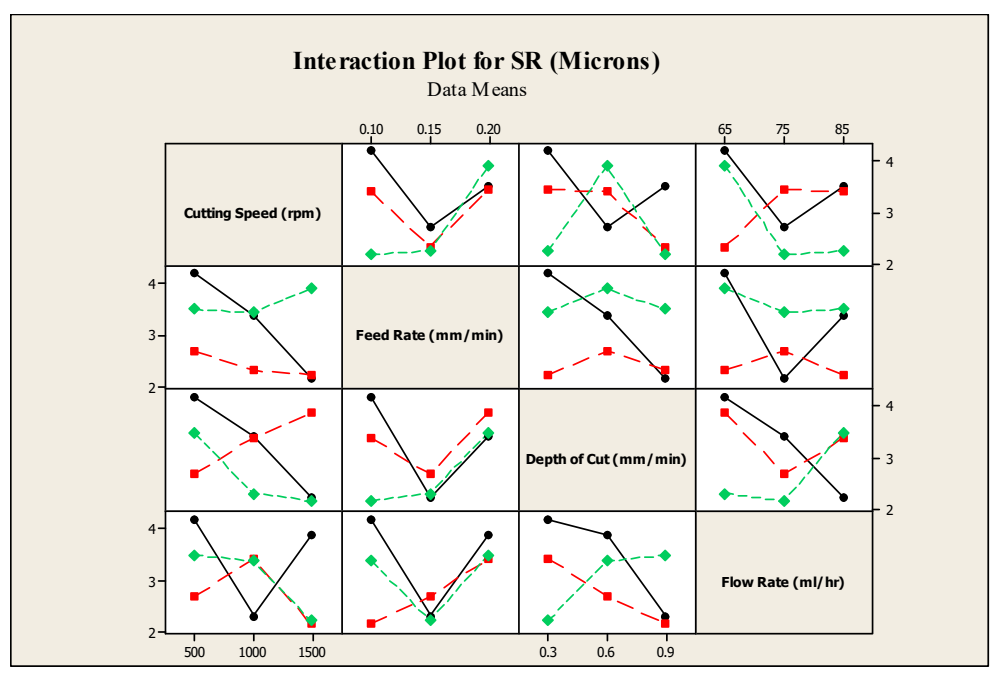

Figure 8. Interaction plot for surface roughness.

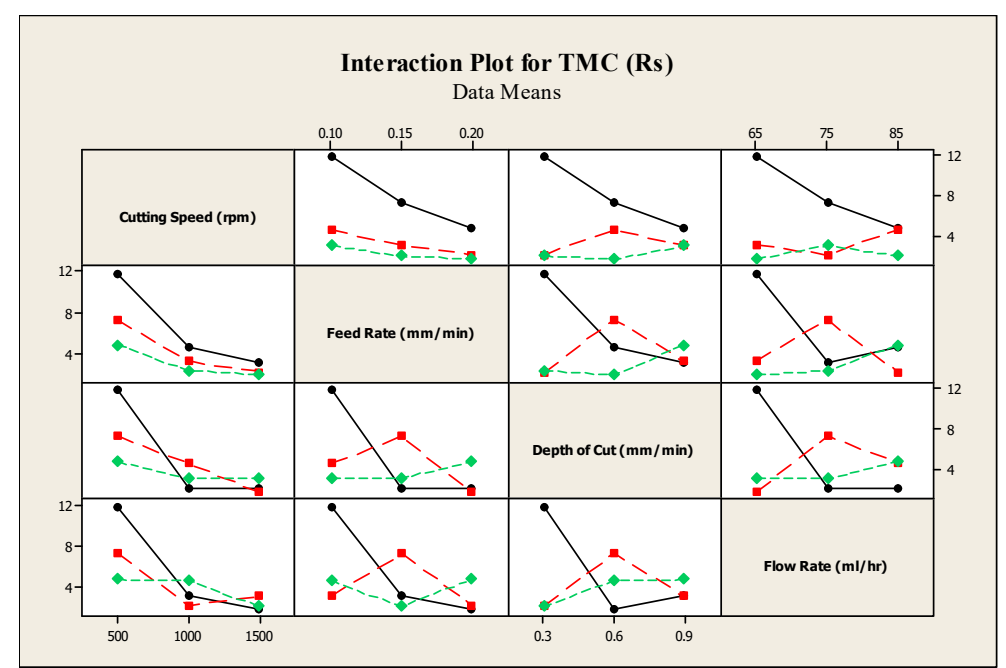

Figure 9. Interaction plot for total machining cost. 


\subsection{ANOVA Analysis on Performance Measures}

Analysis of Variance (ANOVA) is a statistical analysis tool used to determine the significance of process parameters on the performance measures at a $95 \%$ confidence level and it is computed using statistical software Minitab 16.0.

The ANOVA analysis for the desired performance measure is presented in Table 10. From the " $P$ " values, it is observed from the analysis that the cutting speed is the significant process variable for the rate of material removal and the total cost incurred for machining. It is confirmed that the results of ANOVA have a close relationship with Taguchi's response analysis.

Table 5 represents the response analysis table for the material removal rate. From the illustrations, it is clear that the depth of cut is the most predominant process variable which has more influence on the removal of material. Table 6 represents the response analysis table for surface roughness. From the illustrations, it is clear that the feed is the predominant process variable which has more influence on surface roughness. Table 7 represents the response analysis table for total machining cost. From the illustrations, it is clear that the spindle speed is the predominant process variable which has more influence on total machining.

From ANOVA analysis, it is confirmed that Tables 5-7 (Taguchi's response analysis-MRR, SR and TMC) and Table 10 (ANOVA Analysis) show a similar/close relationship among the opted methods for analysis.

Table 10. ANOVA analysis on performance measures.

\begin{tabular}{|c|c|c|c|c|c|c|}
\hline \multicolumn{7}{|c|}{ Analysis of Variance for MRR $\left(\mathrm{mm}^{3} / \mathrm{s}\right)$} \\
\hline Source & DF & Seq SS & Adj SS & Adj MS & $\mathbf{F}$ & $\mathbf{P}$ \\
\hline Cutting speed (rpm) & 2 & 474.35 & 474.35 & 237.17 & 2472.5 & 0 \\
\hline Feed $(\mathrm{mm} / \mathrm{min})$ & 2 & 95.81 & 95.81 & 47.91 & 499.43 & 0 \\
\hline Depth of cut $(\mathrm{mm} / \mathrm{min})$ & 2 & 916.81 & 916.81 & 458.41 & 4778.79 & 0 \\
\hline Flow rate $(\mathrm{mL} / \mathrm{h})$ & 2 & 370.93 & 370.93 & 185.47 & 1933.44 & 0 \\
\hline Error & 18 & 1.73 & 1.73 & 0.1 & - & - \\
\hline Total & 26 & 1859.63 & - & - & - & - \\
\hline \multicolumn{7}{|c|}{ Analysis of Variance for SR (Microns) } \\
\hline Source & DF & Seq SS & Adj SS & Adj MS & $\mathbf{F}$ & $\mathbf{P}$ \\
\hline Cutting speed (rpm) & 2 & 2.2898 & 2.2898 & 1.1449 & 129.94 & 0 \\
\hline Feed $(\mathrm{mm} / \mathrm{min})$ & 2 & 6.8385 & 6.8385 & 3.4193 & 388.06 & 0 \\
\hline Depth of cut $(\mathrm{mm} / \mathrm{min})$ & 2 & 2.5454 & 2.5454 & 1.2727 & 144.44 & 0 \\
\hline Flow rate $(\mathrm{mL} / \mathrm{h})$ & 2 & 2.3185 & 2.3185 & 1.1592 & 131.56 & 0 \\
\hline Error & 18 & 0.1586 & 0.1586 & 0.0088 & - & - \\
\hline Total & 26 & 14.1508 & - & - & - & - \\
\hline \multicolumn{7}{|c|}{ Analysis of Variance for TMC (Rs.) } \\
\hline Source & DF & Seq SS & Adj SS & Adj MS & $\mathbf{F}$ & $\mathbf{P}$ \\
\hline Cutting speed (rpm) & 2 & 164.857 & 164.857 & 82.429 & 917.5 & 0 \\
\hline Feed $(\mathrm{mm} / \mathrm{min})$ & 2 & 60.802 & 60.802 & 30.401 & 338.39 & 0 \\
\hline Depth of cut $(\mathrm{mm} / \mathrm{min})$ & 2 & 13.696 & 13.696 & 6.848 & 76.22 & 0 \\
\hline Flow rate $(\mathrm{mL} / \mathrm{h})$ & 2 & 15.911 & 15.911 & 7.955 & 88.55 & 0 \\
\hline Error & 18 & 1.617 & 1.617 & 0.09 & - & - \\
\hline Total & 26 & 256.882 & - & - & - & - \\
\hline
\end{tabular}

\subsection{Chip Form Analysis and Tool Wear during Machining of LM25 Alloy}

The analysis of the shape of the chip at a constant length of machining with several machining variables was performed and considered with the reference to the ISO-based chip form classification [27]. At the machining condition (1500 rpm, $0.1 \mathrm{~mm} / \mathrm{min}$; higher speed and lower feed), it is observed that the sharpness of the edges of the chip has been considerably abridged that prompted lesser cutting 
force and consecutively good surface finish. From the observations, it is witnessed that at the initial period of machining, the shape of the chip has been continuous and it is changed to a segmented chip as the speed of cutting, feed and depth of machining increases, as illustrated in Figure 10a-e.

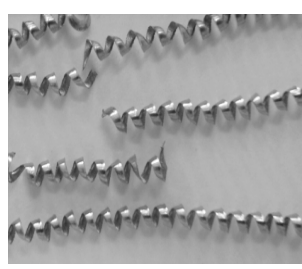

(a)

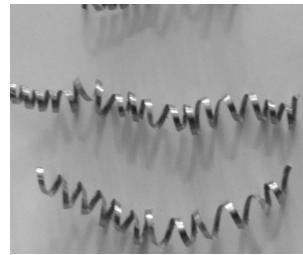

(b)

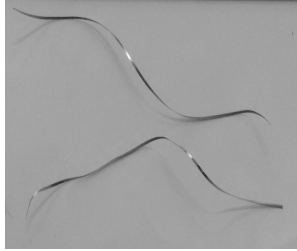

(c)

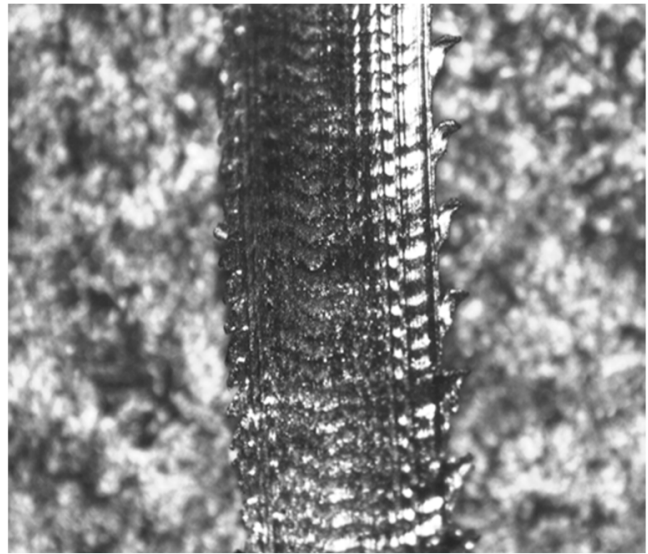

(d)

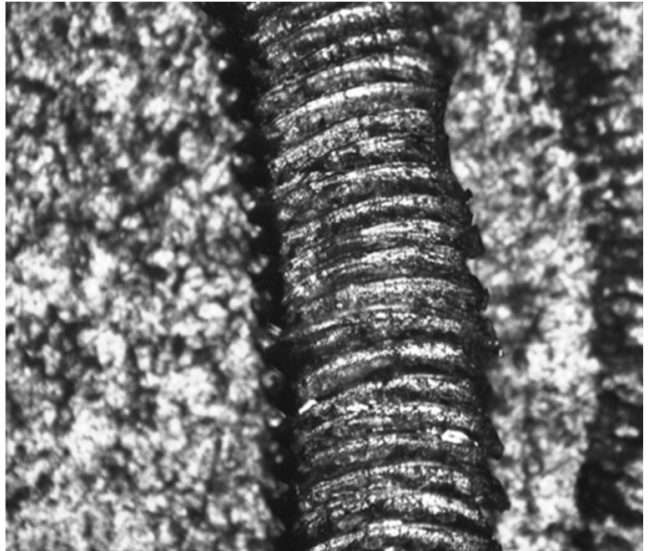

(e)

Figure 10. (a-e) Chips produced at various machining conditions.

The development of flank wear is portrayed because of scouring of the device alongside the surfaces producing adhesive, grating and diffusive kinds of wear and greater temperature that influences the properties of tool and workpiece. It has been seen that for the whole scope of cutting velocities and rate of feed, the device flank wear was observed least. The tool flank wear after machining of LM25 alloy is illustrated in Figure 11.

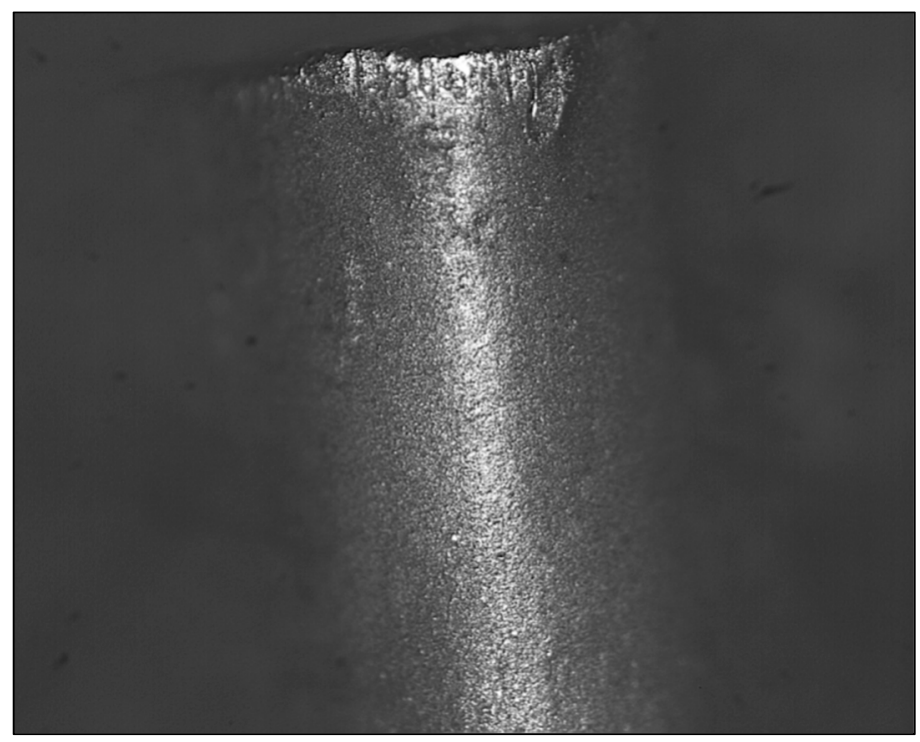

Figure 11. Tool flank wear after machining of LM 25 alloy. 
At the duration of machining with expanded speed, the erosion among the work material and tool is higher than the expanding temperature at the contact point of tool, and consequently, the edge of the tool is made soft and the wear on the tool is impressively expanded due to generation of heat at the flank side. During turning at greater speed, the friction among the work and tool is more than the expansion of the temperature at the work-tool interface, and along these lines, the edge of the tool becomes softened and the wear on the tool is expanded because of the hotness that is produced at the flank side.

\subsection{Confirmation Test for the CNC Turning of LM 25 Alloy}

The confirmation run is a predominant phase to affirm the outcomes based on multi-aspect optimization by the Taguchi Grey approach. The outcome obtained from the proposed approach is confirmed with the experimental run which is performed by executing the combination levels of optimum variables $\left(\mathrm{A}_{3} \mathrm{~B}_{2} \mathrm{C}_{3} \mathrm{D}_{2}\right)$ for getting improved performance in machining for the $\mathrm{CNC}$ turning of LM 25 alloy. The comparison among the starting level and the optimum level of variables are presented in Table 11. It is affirmed from the analysis that the obtained optimum level proves the significant enhancement in machining performance.

Table 11. Confirmation test results for the CNC turning of LM 25 alloy.

\begin{tabular}{lccc}
\hline \multicolumn{4}{c}{ Optimum Machining Parameters } \\
\hline \multirow{2}{*}{ Setting Level } & Initial Setting & Prediction & Experiment \\
\cline { 2 - 4 } & $\mathbf{A}_{\mathbf{1}} \mathbf{B}_{\mathbf{1}} \mathbf{C}_{\mathbf{1}} \mathbf{D}_{\mathbf{1}}$ & $\mathbf{A}_{\mathbf{3}} \mathbf{B}_{\mathbf{2}} \mathbf{C}_{\mathbf{3}} \mathbf{D}_{\mathbf{2}}$ & $\mathbf{A}_{\mathbf{3}} \mathbf{B}_{\mathbf{2}} \mathbf{C}_{\mathbf{3}} \mathbf{D}_{\mathbf{2}}$ \\
\hline MRR (mm $\left.{ }^{3} / \mathrm{s}\right)$ & 2.685 & & 22.62 \\
$\mathrm{SR}($ microns) & 4.09 & 1.31 \\
Total machining cost (rupees) & 11.734 & 0.72 \\
Grey Relational Grade & 0.3467 & 0.9909 & 0.9657 \\
\hline \multicolumn{3}{c}{ Enhancement in Grey Relational Grade } \\
\multicolumn{3}{c}{0.619} \\
\hline
\end{tabular}

\section{Conclusions}

This present investigation dealt with optimizing multiple characters of the CNC turning process variables using Taguchi-based GRA methodology for optimizing the various performance characteristics, namely MRR, roughness of the machined surface and total machining cost. The subsequent decisions were conquered from the analysis:

* Based upon the range and values of cutting parameters considered, the obtained results are valid. From the confirmation test experiments, it is affirmed that the optimum values obtained from the multi-aspects analysis are tested beyond the selected orthogonal array.

* From the analysis of variance, it is observed that the depth of cut is the predominant variable for the material removal rate, and feed and cutting speed are the predominant process variables for surface roughness and total machining cost, respectively.

* From the interaction analysis, it is observed from the interaction plot that the factors of various combinations at all levels make an interactive effect on the material removal rate and surface roughness.

* The application of the Taguchi Grey method offers enriched GRG and improves machining performance and desired performance measures. The assessment results prove that the recommended method can be employed for various machining methods' processes with multiple aspects.

* As a result of optimization, the optimal combination of cutting parameters in turning LM25 aluminum alloy is cutting speed $(A)=1500 \mathrm{rpm}(150.79 \mathrm{~m} / \mathrm{min})$, feed $(B)=0.15 \mathrm{~mm} / \mathrm{min}$, depth of cut $(C)=0.9 \mathrm{~mm}$ and cutting fluid flow rate $(\mathrm{D})=75 \mathrm{~mL} / \mathrm{h}$. Compared with the initial parameter 
settings, surface roughness (Ra) decreases by $67.97 \%$, material removal rate (MRR) increases by $88.12 \%$ and total machining cost (TMC) decreases by $93.86 \%$.

* The results of this present analysis will be extensive support to the industries for improving the quality in processing using the $\mathrm{CNC}$ turning process.

Author Contributions: Conceptualization, S.D. and T.R.; methodology, S.D. and T.R.; software, S.D.; validation, S.D. and T.R.; formal analysis, S.D.; investigation, S.D. and T.R.; resources, S.D. and T.R.; data curation, S.D.; writing—original draft preparation, S.D.; writing—review and editing, S.D. and T.R.; visualization, T.R.; supervision, T.R.; All authors have read and agreed to the published version of the manuscript.

Funding: This research received no external funding.

Conflicts of Interest: The authors declare no conflicts of interest.

\section{References}

1. Davis, J.R. (Ed.) Alloying: Understanding the Basics; ASM International: Cleveland, OH, USA, 2001; pp. 351-416. [CrossRef]

2. Stadler, F.; Antrekowitsch, H.; Fragner, W.; Kaufmann, H.; Pinatel, E.R.; Uggowitzer, P.J. The effect of main alloying elements on the physical properties of Al-Si foundry alloys. Mater. Sci. Eng. A 2013, 560, 481-491. [CrossRef]

3. Dwivedi, D.K. Adhesive Wear Behaviour of Cast Aluminium-Silicon Alloys: Overview. Mater. Des. 2010, 31, 2517-2531. [CrossRef]

4. Nakata, K.; Ushio, M. Wear Resistance of Plasma Sprayed Al-Si Binary Alloy Coatings on A6063 Al Alloy Substrate. Surf. Coat. Technol. 2001, 142-144, 277-283. [CrossRef]

5. Palanikumar, K.; Karunamoorthy, L.; Karthikeyan, R. Optimal Machining parameters for achieving minimal tool wear in turning of GFRP composites. J. Manuf. Sci. Prod. 2004, 6, 119-128. [CrossRef]

6. Songmene, V.; Khettabi, R.; Zaghbani, I.; Kouam, J.; Djebara, A. Machining and machinability of aluminum alloys. Alum. Alloy. Theory Appl. 2011, 377-400. [CrossRef]

7. Nouari, M.; List, G.; Girot, F.; Coupard, D. Experimental analysis and optimisation of tool wear in dry machining of aluminium alloys. Wear 2003, 255, 1359-1368. [CrossRef]

8. Kelly, J.F.; Cotterell, M.G. Minimal lubrication machining of aluminium alloys. J. Mater. Process. Technol. 2002, 120, 327-334.

9. König, W.; Erinski, D. Machinability of Aluminium-Silicon Pressure-Die-Cast Alloys. In Proceedings of the Twentieth International Machine Tool Design and Research Conference; Tobias, S.A., Ed.; Palgrave Macmillan: London, UK, 1980.

10. Kim, J.D.; Kang, Y.H. High-spend machining of aluminium using diamond endmills. Int. J. Mach. Tools Manuf. 1997, 37, 1155-1165. [CrossRef]

11. Sreejith, P.S.; Ngoi, B.K.A. Dry machining: Machining of the future. J. Mater. Process. Technol. 2000, 101, 287-291. [CrossRef]

12. Carrilero, M.S.; Bienvenido, R.; Sánchez, J.M.; Alvarez, M.; González, A.; Marcos, M. A SEM and EDS insight into the BUL and BUE differences in the turning processes of AA2024 Al-Cu alloy. Int. J. Mach. Tools Manuf. 2002, 42, 215-220.

13. Nataraj, M.; Balasubramanian, K. Parametric Optimization of CNC Turning Process for Hybrid Metal Matrix Composite. Int. J. Adv. Manuf. Technol. 2017, 93, 215-224. [CrossRef]

14. Sahoo, A.K.; Pradhan, S. Modeling and optimization of Al/SiCp MMC machining using Taguchi approach. Measurement 2013, 46, 3064-3072. [CrossRef]

15. Zhou, L.; Cui, C.; Zhang, P.F.; Ma, Z.Y. Finite Element and Experimental Analysis of Machinability during Machining of High-Volume Fraction SiCp/Al Composites. Int. J. Adv. Manuf. Technol. 2017, 91, 1935-1944. [CrossRef]

16. Rajesh, S.; Devaraj, D.; Sudhakara Pandian, R.; Rajakarunakaran, S. Multi-Response Optimization of MachiningParameters on Red Mud-Based Aluminum Metal Matrix Composites in Turning Process. Int. J. Adv. Manuf. Technol. 2013, 67, 811-821. [CrossRef]

17. Yu, Q.; Li, S.; Zhang, X.; Shao, M. Experimental Study on Correlation between Turning Temperature Rise and Turning Vibration in Dry Turning on Aluminum Alloy. Int. J. Adv. Manuf. Technol. 2019, 1-17. [CrossRef] 
18. Upadhyay, V.; Jain, P.K.; Mehta, N.K. In-process prediction of surface roughness in turning of Ti-6Al-4V alloy using cutting parameters and vibration signals. Measurement 2013, 46, 154-160. [CrossRef]

19. Grzesik, W. Advanced Machining Processes of Metallic Materials; Elsevier: Amsterdam, The Netherlands, 2008.

20. Deng, J. Introduction to grey system. J. Grey Syst. 1989, 1, 1-24.

21. Tripathy, S.; Tripathy, D.K. Multi-attribute optimization of machining process parameters in powder mixed electro-discharge machining using TOPSIS and grey relational analysis. Eng. Sci. Technol. Int. J. 2016, 19, 62-70. [CrossRef]

22. Palanisamy, D.; Devaraju, A.; Harikrishnan, S.; Manikandan, N. Machinability studies on CNC turning of PH stainless steel with Coated Inserts. Mater. Today Proc. 2018, 5, 14520-14525. [CrossRef]

23. Su, Y.; Zhao, G.; Zhao, Y.; Meng, J.; Li, C. Multi-Objective Optimization of Cutting Parameters in Turning AISI 304 Austenitic Stainless Steel. Metals 2020, 10, 217. [CrossRef]

24. Gopalakrishnan, B.; Al-Khayyal, F. Machine parameter selection for turning with constraints: An analytical approach based on geometric programming. Int. J. Prod. Res. 1991, 29, 1897-1908. [CrossRef]

25. Lamond, B.F.; Sodhi, M.S. Using tool life models to minimize processing time on a flexible machine. IIE Trans. 1997, 29, 611-621. [CrossRef]

26. Akturk, M.S.; Avci, S. Tool allocation and machining conditions optimization for CNC machines. Eur. J. Oper. Res. 1996, 94, 335-348. [CrossRef]

27. Trent, E.M.; Wright, P.K. Metal Cutting, 4th ed.; Elsevier Publisher: Chennai, India, 2006.

28. Julong, D. Introduction to grey system theory. J. Grey Syst. 1989, 1, 1-24.

29. Antony, J. Design of Experiments for Engineers and Scientists; Elsevier: Amsterdam, The Netherlands, 2014.

(C) 2020 by the authors. Licensee MDPI, Basel, Switzerland. This article is an open access article distributed under the terms and conditions of the Creative Commons Attribution (CC BY) license (http://creativecommons.org/licenses/by/4.0/). 